\title{
OS USOS SOCIAIS DA MÚSICA: UMA REFLEXÃO SOBRE OS DESDOBRAMENTOS DA MÚSICA DE PROTESTO, A LUTA POR PARTICIPAÇÃO SOCIAL E LIBERDADE INDIVIDUAL
}

Marcelo Saldanha das Neves

Universidade do Oeste Paulista, Curso de Licenciatura em Música, Presidente Prudente, SP. E-mail: marcelo muc@hotmail.com

\section{RESUMO}

A década de 60 compreende um movimento de ordem política e ideológica, denominado Música de Protesto, que culminou em diversas expressões artísticas como forma de subversão aos valores estabelecidos pela sociedade deste período e seu regime de governo ditatorial. O presente artigo teve como objetivo investigar a relação do movimento em questão com as demais manifestações artísticas por participação social que o sucedem. Foram analisados materiais bibliográficos, fonográficos e visuais que discutem o movimento, a organização de grupos sociais buscando participação e a ação artística de outros grupos que representavam transgressão aos valores morais e civis da sociedade brasileira na década de 70. 0 movimento da Música de Protesto diante desse momento social repressivo desencadeou uma expansão criativa nas produções artísticas como forma de reivindicar liberdade política e individual.

Palavras-chave: Música de Protesto, Regime Militar, Participação Social, Grupos Sociais, Expressões Artísticas.

THE SOCIAL USES OF MUSIC: A REFLECTION ON THE CONSEQUENCES OF PROTEST MUSIC, THE FIGHT FOR SOCIAL PARTICIPATION AND INDIVIDUAL FREEDOM

\begin{abstract}
The 60's comprise a political and ideological movement, named Protest Music, it culminated in various artistic expressions as a way of subverting the values established by the society this period and its dictatorial government regime. This article aims to investigate the relationship of this movement with other art forms for social participation that succeed. They were analyzed bibliographic, phonographic and visual materials that discuss the movement, the organization of social groups seeking participation and artistic action of other groups representing transgression of moral and civil values of Brazilian society in the 70's. The Protest Music movement before this repressive social moment sparked a creative expansion in artistic productions as a way to vindicate political and individual freedom.
\end{abstract}

Keywords: Protest Music, Military Regime, Social Participation, Social Groups, Artistic Expressions. 


\section{INTRODUÇÃO}

A música, como uma prática social, revela contextos bastante complexos das relações existentes na esfera pública. Se a analisarmos atrelada a história da sociedade brasileira perceberemos uma série de momentos onde foi utilizada como instrumento de manutenção das relações hegemônicas entre classes, características das sociedades capitalistas industrializadas.

No Brasil, este movimento teve forte influência até o século $X X$, quando as classes negligenciadas em participação social ofereceram resistência ao regime de governo, utilizando-se para isso das próprias manifestações artísticas. Na segunda metade do século XX, mais precisamente após o Golpe de 1964 que trouxe ao Brasil a consolidação de um governo ditatorial, o fazer musical se direcionou também a denunciar a repressão que se instaurou no país, vários artistas dedicaram suas obras a reunir elementos que revelavam discordância às condutas arbitrarias do governo militar.

Dentre estes elementos podemos ressaltar diversos signos que rementiam a necessidade de desconstrução de papeis sociais. Este momento histórico específico nos sugere uma análise para além das discussões de classe, mas também um olhar para as discussões de sexualidade, gênero e machismo que circundam na perspectiva de liberdades individuais.

A Música de Protesto, considerada por alguns autores como um movimento político e ideológico, emerge em um momento bastante singular da história brasileira que precisa ser visto como um possível condicionante das manifestações políticas ali presentes. O momento em questão representa um limite significativo para a expressão através das obras artísticas, visto que aquelas que apresentassem conteúdo crítico ou denunciatório seriam censuradas e aqueles que a compuseram/interpretaram seriam presos ou exilados.

As músicas de protesto foram produzidas em um contexto bastante conturbado da história do Brasil. Seu período de consolidação/extinção foi de extrema repressão. Houve suspensão de direitos políticos e individuais. $\mathrm{E}$ a institucionalização da tortura como método de interrogatório. O Al-5 atingiu inúmeros cantores e compositores, a maioria ligada à MPB (Música Popular Brasileira) que tentaram driblar a censura. Muitos foram exilados e torturados, entre eles: Chico Buarque, Gilberto Gil, Caetano Veloso, Geraldo Vandré, Nara Leão, entre outros.

(PAIXÃO e VIEIRA, 2013, ps. 01 e 02).

A luta contra a repressão não se deu apenas através dos artistas que emergiram o movimento de protesto, mas na sequência por diversos grupos e movimentos sociais que visavam participação social e desconstrução dos papéis sociais vigentes, colocando-se na luta pela garantia de direitos políticos e individuais. A música neste sentido teve uma função central devido a sua popularização nos festivais que aconteciam em grandes emissoras de TV e na sua circulação massiva através dos demais meios de comunicação.

Esta circulação favoreceu as bases de um fenômeno conhecido como Indústria Cultural que colocou os objetos culturais na lógica de produção industrial. Este fenômeno resultou na simplificação da produção musical, pois enquanto produto, quanto mais pessoas alcançasse mais interessante economicamente ela seria.

Napolitano (2002) ressalta as contradições do movimento de protesto, uma vez que mesmo enquanto denunciava, utilizava-se dos mecanismos da Indústria Cultural para isso. Porém, sua reflexão traz à MPB, grande representante do movimento, um estatuto além da mercadoria devido a sua importância e complexidade diante do momento social em que se insere.

Essa dicotomia esteve presente durante todo o movimento da Música de Protesto e não foi diferente nas décadas que o seguem, afinal quem produzia o material musical não eram exatamente as pessoas mais pobres e menos participativas na sociedade e sim, em sua maioria, os 
jovens universitários de classe média. Estes jovens fortemente influenciados por ideias revolucionárias de partidos políticos de esquerda e movimentos estudantis provocaram uma ruptura na segmentação do movimento, expandindo seus eixos de ação e influência social.

Por volta de 1978, a MPB, compreendida em todas as suas variáveis estilísticas e esferas de influência social, era o setor mais dinâmico da indústria fonográfica brasileira, ao mesmo tempo que readquiria sua vitalidade como "instituição" sociocultural e seu caráter aglutinador dos sentimentos da oposição civil. As cifras de vendagem dos chamados "monstros sagrados" (Chico Buarque, Elis Regina, Maria Bethania, entre outros) confirma tal afirmação. Ao mesmo tempo, sua penetração em faixas de públicos mais amplas, fora dos extratos mais intelectualizados e exclusivamente universitários da classe média alta, desempenhou um importante papel na "educação sentimental" e política de uma geração inteira de jovens, principalmente a chamada geração Al-5. No último terço da década de 70, essa pouco comum confluência de popularidade comercial e reconhecimento estético, parece ter marcado a história da MPB.

(NAPOLITANO, 2002, p. 11).

Este trabalho se direciona não somente as discussões referentes ao movimento da Música de Protesto emergente nos anos 60, mas também e principalmente aos seus desdobramentos nas décadas seguintes. As músicas compostas por grupos transgressores perante os valores trazidos pelo regime militar revelavam manifestações em busca de participação social. Alguns artistas a partir da década de 70, destacando o grupo "Secos e Molhados" e o grupo "Dzi Croquetes", trouxeram em suas apresentações referências de outras discussões centrando principalmente nas normas de gênero e no machismo.

Podemos dizer que ao longo do período que vai de 1972 a 1975 (aproximadamente), o espaço social, cultural e comercial da MPB, começava a se rearticular, ainda que timidamente. Alguns fatos marcaram este processo: a volta dos compositores exilados (Chico, Caetano, Gil), a paulatina consolidação de um novo conjunto de revelações (Ivan Lins, Fagner, Belchior, Alceu Valença, João Bosco/ Aldir Blanc), o retorno de Elis Regina ao primeiro plano de cenário musical (com "águas de março" o LP Elis e Tom), o novo alento à música brasileira representada pela meteórica trajetória de Ney Matogrosso e os "Secos e Molhados" e pelo sucesso de Raul Seixas, foram sinais de vitalidade e criatividade num ambiente social e musical desgastado e sem perspectivas.

(NAPOLITANO, 2012, p. 07).

O grupo "Secos \& Molhados" trouxe aos palcos uma performance transgressora. Os integrantes utilizavam bastante maquiagem e roupas repletas de acessórios transitando entre a dicotomia "homem e mulher". As danças trazidas por Ney Matogrosso, vocalista do grupo, exploravam movimentos sensuais pouco representantes da "masculinidade" enquanto um campo de significados, colocando em cheque os papeis de gênero e sexualidade impostos.

O grupo ainda trazia letras e estruturas musicais com elementos de alguns movimentos vanguardistas da música popular na época, representando a emergência criativa oriunda no movimento da Música de Protesto. O segundo grupo citado, "Dzi Croquettes", também utilizou do palco como uma forma de questionamento dos limites de papeis de gênero e sexualidade, uma 
vez que era composto por homens que se apresentavam maquiados, heterogeneizando elementos simbólicos dos campos de significado ditos "feminino" e "masculino".

Para antropóloga citada, o Dzi Croquettes respondeu de maneira prática aos fenômenos de rigidez e intolerância em um período onde ser artista era visto como sinal de vadiagem e ameaça ao poder público vigente. Eles não combateram com armas, mas com a arte, ou melhor, fizeram da arte uma arma; resistindo às históricas e rígidas normas de gênero.

(SILVA, 2014, p. 02).

As apresentações do grupo aproximavam a música do protesto quando contestava os limites destas normas de gênero, mas não somente, também incorporava a discussão de masculinidade, reconfigurando seus limites. Treze homens dentro de um palco exploravam diversas formas de se manifestar enquanto "homens", ampliando assim os limites até então intransponíveis da masculinidade.

A masculinidade naquele momento, segundo SILVA (2014), revela uma condição de "macho" que se manifesta em diversos campos simbólicos, sendo padronizadamente branca, heterossexual e viril, considerando ainda seu mantimento através de uma perspectiva violenta, pois se coloca em um grau de superioridade diante das outras expressões de gênero. Esta mesma quando questionada pelos grupos artísticos em questão mostra que não é um campo rígido e único de expressão e deve ser reconstruída sobre bases de maior liberdade, sendo possível afirmar que não existe "masculinidade" e sim "masculinidades".

Todas estas apresentações musicais convergiriam com a discussão do ativismo gay de 1978 e a necessidade de organização pela busca da garantia de liberdade sexual, desconstrução de papeis de gênero e da masculinidade. A luta feminista também esteve próxima deste movimento buscando o fim de uma cultura extremamente machista.

O desafio das feministas ao patriarcado, à rigidez dos papeis de gênero e aos costumes sexuais tradicionais desencadeou uma discussão na sociedade brasileira que convergiu com as questões levantadas pelo movimento gay a partir de 1978. Ativistas gays e muitas feministas viram uns aos outros como aliados naturais contra o sexismo e uma cultura dominada pelo machismo.

(GREEN, 2013, p. 01 e 02).

O cerceamento das liberdades imposto pelo regime militar compreendeu diversos grupos sociais e isso fica bastante evidente após o movimento da música de protesto, quando estes grupos se colocam socialmente através da expressão artística. As mulheres, homossexuais e travestis compreendem os grupos que antes invisibilizados, na década de 70 de forma incisiva iniciam sua luta por participação social através das manifestações artísticas.

Esses grupos utilizaram da arte para questionar a hierarquização de direitos entre grupos sociais e a ausência de liberdade de expressão individual. Sua luta coincide com a necessidade de desestruturação de uma cultura machista que se valia de seus valores para homogeneizar a sociedade e consequentemente neutralizar as diversidades, fossem elas de sexo, gênero ou expressão cultural.

Destacando a música como um campo de exercício destas diversidades, este trabalho visa refletir sobre os desdobramentos do movimento da Música de Protesto, enquanto condicionantes de uma abertura na expressão artística e na participação de grupos sociais. 


\section{METODOLOGIA}

O movimento da Música de Protesto nos permite observá-la através da perspectiva social como uma manifestação de resistência frente às estruturas de dominação política. Este trabalho surge desta perspectiva e da necessidade de observar também os desdobramentos deste movimento político e ideológico na sociedade brasileira.

Foca-se nas expressões subversivas a uma cultura extremamente machista que se instaurou no país e esteve fortalecida durante o regime militar. A observação de materiais bibliográficos, fonográficos e visuais de diversos grupos favoreceu esta reflexão. Estes materiais estabelecem uma relação entre a repressão social, a emergência do movimento da Música de Protesto e o consequente protesto através da expressão artística nas décadas que o sucedem, principalmente no que tange a liberdade sexual, a desconstrução de normas de gênero e o rompimento com uma cultura machista.

A realização destas reflexões e relações se deu também através da exploração de materiais acadêmicos que discutem o Movimento da Música de Protesto, a Indústria Cultural e a produção artística da década de 60 e 70. Tendo como eixo a produção musical, mas ampliando o debate também para materiais visuais de alguns grupos que representaram protagonismo nas lutas citadas no parágrafo anterior.

Napolitano (2002) traz uma referência bastante importante de materiais fonográficos que representam o movimento em questão, tendo entre eles artistas como: Chico Buarque, Caetano Veloso, Elis Regina, Geraldo Vandré, Ivan Lins, Ney Matogrosso e o grupo "Secos \& Molhados", Raul Seixas, entre outros. Esta diversidade sonora representa a diversidade social que vai buscar sua participação nas décadas que sucedem o movimento da Música de Protesto.

Além destes artistas, ressalta-se segundo Green (2000), a presença do Grupo "Dzi Croquettes" na década de 70 e também a presença de travestis na vida cultural dos grandes centros urbanos, fomentando as lutas sobre as quais se desenvolve este trabalho. Todos estes grupos e nomes específicos se encontram na busca por participação em uma sociedade de extrema repressão, principalmente após o Al-5, ato institucional do governo que favoreceu a censura e perseguição dos artistas que apresentassem em suas obras críticas relacionadas ao regime militar.

Os materiais bibliográficos, fonográficos e visuais aqui analisados oportunizaram uma relação profunda entre o momento repressivo do regime militar pós-golpe de 1964 e a produção artística que o sucede. Os artistas a partir da década de 70 ousam na produção de seus materiais, que mesmo confluentes à dinâmica da Indústria Cultural manifestam uma importância simbólica na luta por participação social e exercício da diversidade.

\section{RESULTADOS}

Os resultados deste trabalho se apresentam em forma de reflexões direcionadas a um momento bastante específico da história musical e social do nosso país. Nas décadas de 60 e 70 diversos artistas da Música Popular Brasileira viram em suas obras uma possibilidade de militância pela garantia de direitos. Esta luta se deu durante um regime de governo que visava homogeneizar as relações sociais através de padrões de comportamento e conduta civil. Os desdobramentos do movimento da Música de Protesto se revelam muito além da década de 60 e vão ao encontro da busca pelo exercício da liberdade política e das liberdades individuais repreendidas pelo governo que se instaurou no momento histórico em questão.

\section{DISCUSSÃO}

Como a Música de Protesto culmina em diferentes manifestações artísticas de protesto? Quais eram as liberdades requeridas por aqueles que utilizavam da arte como militância? Como 
mesmo atrelada à dinâmica da Indústria Cultural, a música pode representar subversão aos valores políticos instaurados? Estas questões orientam a construção deste trabalho e nos colocam diante de um período histórico em que a sociedade brasileira teve na arte uma expressão do desejo de transformação de uma situação repressiva.

Estabelece-se aqui uma discussão entre os limites rompidos pelo movimento da Música de Protesto, investigando as diversas manifestações expressivas contrárias a uma cultura machista e a necessidade de desconstrução dos papeis de gênero e sexualidade vigentes. Também é investigado o paradoxo entre uma música que deve atender aos interesses de mercado e ainda assim se manifestar contraditória ao governo vigente.

\section{CONCLUSÃO}

O movimento da Música de Protesto é apresentado por alguns autores como bastante paradoxal, pois fazia parte da dinâmica da Industrial Cultural e emergiu nas classes médias da sociedade que não representavam as mais inferiores em participação, mas segundo Napolitano (2002) ainda assim sua importância não deve ser subjulgada, devido ao seu grau de complexidade na relação com o momento social em questão.

O movimento de protesto inicia na década de 60 diante de todos os acontecimentos políticos que demarcam este momento, mas tem na década seguinte uma ampliação no eixo de luta, sendo incorporado por grupos sociais que reivindicavam o direito ao exercício de suas liberdades de sexo e gênero e sua participação social.

Olhar para a Música de um determinado período histórico é também olhar para as diversas expressões sociais e políticas que influenciaram sua construção, distribuição e apreciação. Sendo assim, quando observamos a música realizada nas décadas de 60 e 70 compreendemos sua relevância diante de uma sociedade reprimida em suas liberdades tanto sociais quanto individuais. O movimento tem forte influência na criação musical, mas não se restringe a ela, pois incorpora as outras manifestações artísticas na luta por participação social e exercício da liberdade individual.

\section{REFERÊNCIAS}

AVRITZER, L. Teoria democrática, esfera pública e participação local. Revista Sociologias. Porto Alegre ano 1, no. 2, 1999.

GREEN, J. N. Além do Carnaval: A homossexualidade masculina no Brasil do século XX; tradução: Cristina Fino e Cássio Arantes Leite. São Paulo: Editora UNESP, 2000.

LOBERT, R. A Palavra Mágica: a vida cotidiana dos Dzi Croquettes. Campinas: Editora Unicamp, 2010.

NAPOLITANO, M. A Música Popular Brasileira (MPB) dos anos 70: resistência política e consumo cultural. In: IV Congresso de La Rama latinoamericana de IASPM. Cidade do México: IASPM, 2002.

PAIXÃO, L. A. VIEIRA, F. dos S. O Movimento da Música de Protesto no Brasil (1961-1968). In: Encontro de Produção Científica e Tecnológica. Campo Mourão: NUPEM, 2013.

SILVA, N de F. Dzi Croquettes: "Nem homem, nem mulher, gente". Masculino e masculinidades. In: Encontro Regional de História da Anpuh-Rio: Saberes e Práticas Científicas. Rio de Janeiro: ANPUH RIO, 2014.

TINHORAO, J. R. Pequena história da música popular: da modinha à canção de protesto. Petrópolis: Vozes, 1974. 